\title{
Association of PM2.5 and its Components with Lengths of Hospital Stay for Hand Foot and Mouth Disease in Children
}

\section{Wei Li ( $\square$ weili126@126.com )}

Children's Hospital of Nanjing Medical University

\section{Jieguo Wang}

Children's Hospital of Nanjing Medical University

\section{Kai Zhou}

Children's Hospital of Nanjing Medical University

\section{Ye Tian}

Children's Hospital of Nanjing Medical University

\section{Feiran Wei}

Southeast University Zhongda Hospital

Mingzhi Zhang

Nanjing Medical University

Xu Wang

Children's Hospital of Nanjing Medical University

\section{Research Article}

Keywords: PM2.5, Components, Lengths of hospital stay, Hand foot and mouth disease, Children, Association

Posted Date: December 20th, 2021

DOI: https://doi.org/10.21203/rs.3.rs-986232/v2

License: (a) (1) This work is licensed under a Creative Commons Attribution 4.0 International License. Read Full License 


\section{Abstract \\ Background}

Hand foot and mouth disease (HFMD) is a public health concern. Studies on air pollution and the lengths of hospital stay (LOS) of HFMD are scarce.

\section{Methods}

We characterized the clinic demographic features of 5135 hospitalized HFMD in Nanjing, China from 2012 to 2017, and analyzed the association between short-term exposure to $\mathrm{PM}_{2.5}$ as well as its components (OM, BC, $\mathrm{SO}^{2-}{ }^{-}, \mathrm{NH} 4^{+}, \mathrm{NIT}$, SOIL and SS) and the LOS of HFMD.

\section{Results}

Among them $98.62 \%$ were aged $0-6$ years old, and 3772 (73.46\%) were hospitalized for seven days or less. The LOS of HFMD children was different in different ages, illness onset years and illness onset seasons $(P<0.01)$. For per IQR increase in $\mathrm{PM}_{2.5}$ concentrations, LOS of HFMD increased by $0.52(0.33$, $0.71), 0.50(95 \% \mathrm{Cl}, 0.31-0.69)$ and $0.46(95 \% \mathrm{Cl}, 0.28-0.65)$ day in adjusted models at lag 3 days, lag 7days and lag 14 days, respectively. In addition, per IQR increase of $\mathrm{BC}, \mathrm{SO}_{4}{ }^{2-}, \mathrm{NH}_{4}{ }^{+}, \mathrm{NIT}$ and SOIL were also significantly associated with the LOS of HFMD.

\section{Conclusions}

Our findings corroborated the hypothesis that short-term $\mathrm{PM}_{2.5}$ exposure was associated with increased the LOS of HFMD, and its components (BC, $\mathrm{SO}_{4}{ }^{2-}, \mathrm{NH}_{4}{ }^{+}$, NIT and SOIL) of $\mathrm{PM}_{2.5}$ might play a key role in the prolonged LOS of HFMD.

\section{Introduction}

Hand foot and mouth disease (HFMD) is a public health concern (Chang et al. 1998, Ma et al. 2010). It is caused by a variety of human intestinal viruses, most commonly by enterovirus 71 (EV71) and coxsackievirus A16 (CVA16) (Blomqvist et al. 2010, Han et al. 2014, Mirand et al. 2012), and is a common infectious disease in infants and young children under 5 years of age with fever and rash or herpes on hands, feet, mouth and other parts(Repass et al. 2014). This disease is distributed globally and widespread in Asia, especially in the East and South Asia(Duan et al. 2018, Hu et al. 2012, Koh et al. 2016, Wang et al. 2013, Zou et al. 2012). In May 2008, China made HFMD as a statutory infectious disease, and the National Health and Health Committee of China officially issued the "Hand foot and mouth disease Treatment Guide (2018 Edition)". During 2008-2015, a total of 398,010 HFMD patients with >2 episodes 
were reported among children in China (Huang et al. 2018). The general cases lasting for 7 to 10 days, however, some theses severe cases need prolonged hospitalization, the longer lengths of hospital stay (LOS) of HFMD will increase the chance of infection in the hospital and increases the cost of hospitalization.

Due to the long survival period of HFMD related intestinal virus in ambient air, air pollutants may play a critical role in HFMD epidemics(Hao et al. 2020). Previous studies have indicated that air pollutants are significantly related to HFMD incidence in children(Huang et al. 2019). As $\mathrm{PM}_{2.5}$ is one of the major air pollutants in the world and severe to health, good air quality might protect against HFMD(Yu et al. 2019). Improving air quality, especially decreasing PM $_{2.5}$ could decrease the risk of HFMD outbreaks(Zhong et al. 2018). $\mathrm{PM}_{2.5}$ is a complex mixture of inorganic and organic compounds, the main components of $\mathrm{PM}_{2.5}$ include organic matter (OM), black carbon (BC), sulfate $\left(\mathrm{SO}_{4}{ }^{2-}\right)$, ammonium $\left(\mathrm{NH}_{4}{ }^{+}\right)$, nitrate (NIT), SOIL, sea salt (SS), trace element oxides, and others(Li et al. 2016, Nunez et al. 2021, Tian et al. 2020). Most of the research indicated that an exceedance of $\mathrm{PM}_{2.5}$ level of the standards could lead to varying degrees of health hazards based on $\mathrm{PM}_{2.5}$ chemical constituents(Mukherjee \&Agrawal 2018). But these studies have focused on adult hospital admissions or mortality, however, few studies have focused on the association between $\mathrm{PM}_{2.5}$ and its chemical components and the LOS of HFMD.

In our study, we characterized the clinic demographic features of hospitalized HFMD in Nanjing, China, focusing on age, gender, illness onset year, illness onset season, as well as geographical patterns. We evaluated HFMD cases exposure to $\mathrm{PM}_{2.5}$ and its main components, aimed to evaluate the association between short-term exposure to $\mathrm{PM}_{2.5}$ and its components and the LOS of HFMD, to test the hypothesis that specific chemical component of $\mathrm{PM}_{2.5}$ is responsible for $\mathrm{PM}_{2.5}$ associated the LOS of HFMD.

\section{Methods}

\section{Study Design and Participants}

\section{Population}

The clinical data collected from Children's Hospital of Nanjing Medical University between January 2012 and December 2017 were analyzed retrospectively. 5135 hospitalized Nanjing children with HFMD were diagnosed by a professional pediatrician. Their medical histories were abstracted from medical records. The study was approved by the Ethics Committee of Children's Hospital of Nanjing Medical University. Data used in this work were anonymous, and no individually identifiable information was available here.

\section{Clinic Demographic Features Of Participants}

After admission, a face-to-face interview was conducted by the professional pediatrician to collect data on children's characteristics, including age, gender, illness onset season and illness onset year. All HFMD 


\section{Modeling Pm And Its Components Concentrations}

The geocoded residential addresses of all 5135 HFMD cases were linked to the average modeled concentrations of $\mathrm{PM}_{2.5}$ and its constituents. We evaluated the residential children exposure to $\mathrm{PM}_{2.5}$ and its seven main constituents (OM, BC, SO $4^{2-}, \mathrm{NH}_{4}^{+}, \mathrm{NIT}$, SOIL and SS) 3,7 and 14 days prior to hospitalization using the V4.CH.02 product of the Dalhousie University Atmospheric Composition Analysis Group (ACAG) (van Donkelaar et al. 2016, van Donkelaar et al. 2019).

\section{Statistical analysis}

First, we estimated the characteristics of age, gender, illness onset season (spring (from March to May), summer (from June to August), autumn (from September to November) and winter (from December to February)), illness onset year and LOS on 5135 hospitalized children living in Nanjing with HFMD. Cases' residential addresses were collected from the hospital medical records. The geographic location of children at home was converted to latitude and longitude and described in Figure 1. Then we explore age, gender, illness onset season and illness onset year parameters by specific LOS. Correlation between each component of $\mathrm{PM}_{2.5}$ was calculated by Pearson correlation analysis. Multiple linear regression models were performed to examine the associations between (1) per interquartile range (IQR) increase in $\mathrm{PM}_{2.5}$ and its components and the LOS of HFMD in lag 3 days; (2) per IQR increase in $\mathrm{PM}_{2.5}$ and its components and the LOS of HFMD in lag 7 days; (3) per IQR increase in $\mathrm{PM}_{2.5}$ and its components and the LOS of HFMD in lag 14 days. Model 1 was unadjusted, Model 2 was adjusted for age, gender, illness onset year and illness onset season. FDR corrections were conducted to correct the $p$-values due to the multiple comparisons. All analyses were performed using R software (version 3.6.1, R Core Team 2019).

\section{Results}

\section{Study population characteristics}

We described the characteristics of 5135 hospitalized HFMD children. The majority were boys (64.32\%). The mean age was 1.99 years (standard deviation [SD]: 1.48) (Table 1), and 5064 (98.62\%) were aged 06 years old. Among all patients, 3772 (73.46\%) were hospitalized for seven days or less. There are two epidemic cycles in summer and autumn. There were no deaths, and all of them were discharged from the hospital. 
Table 1

Characteristics of 5135 hospitalized children living in Nanjing with hand foot mouth disease.

\begin{tabular}{|ll|}
\hline Characteristic & $\mathbf{N}(\%)$ or Mean \pm SD \\
\hline Age (year) & $1.99 \pm 1.48$ \\
\hline $1-6$ & $2664(51.88)$ \\
\hline$>6$ & $2400(46.74)$ \\
\hline Gender & $71(1.38)$ \\
\hline boy & \\
\hline girl & $3303(64.32)$ \\
\hline Illness onset year & $1832(35.68)$ \\
\hline 2012 & \\
\hline 2013 & $762(14.80)$ \\
\hline 2014 & $1048(20.41)$ \\
\hline 2015 & $919(17.90)$ \\
\hline 2016 & $836(16.28)$ \\
\hline 2017 & $964(18.77)$ \\
\hline Illness onset season & $606(11.80)$ \\
\hline spring & $122(2.38)$ \\
\hline summer & $882(17.18)$ \\
\hline autumn & $1606(31.28)$ \\
\hline winter & $1646(32.05)$ \\
\hline Hospital length of stay (day) & \\
\hline$\leq 7$ & $1001(19.49)$ \\
\hline $7-14$ & \\
\hline$>14$ & \\
\hline
\end{tabular}

According to Table 2, the results showed that the LOS of HFMD children was different in different ages, illness onset years and illness onset seasons $(P<0.01)$. The LOS of HFMD between gender was not significantly different $(P=0.91)$. 
Table 2

Parameters by specific length of hospital stay among 5135 children.

\begin{tabular}{|c|c|c|c|c|}
\hline \multirow[t]{2}{*}{ Characteristic } & \multicolumn{3}{|c|}{ Length of hospital stay(days) } & \multirow[t]{2}{*}{$p$} \\
\hline & $\leq 7(n=3772)$ & $7-14(n=1241)$ & $>14(n=122)$ & \\
\hline Age (year) & & & & $<0.01$ \\
\hline$\leq 1$ & $2019(53.53)$ & $793(63.90)$ & $31(25.41)$ & \\
\hline $1-6$ & $1693(44.88)$ & $448(36.10)$ & $90(73.77)$ & \\
\hline$>6$ & $60(1.59)$ & $0(0)$ & $1(0.01)$ & \\
\hline Gender & & & & 0.91 \\
\hline boy & $2430(64.42)$ & $793(63.90)$ & $80(65.57)$ & \\
\hline girl & $1342(35.58)$ & $448(36.10)$ & $42(34.43)$ & \\
\hline Illness onset year & & & & $<0.01$ \\
\hline 2012 & $487(12.91)$ & $233(18.78)$ & $42(34.43)$ & \\
\hline 2013 & 779 (20.65) & $243(19.58)$ & $26(21.31)$ & \\
\hline 2014 & $644(17.07)$ & $247(19.90)$ & $28(22.95)$ & \\
\hline 2015 & $690(18.29)$ & $142(11.44)$ & $4(3.28)$ & \\
\hline 2016 & $749(19.86)$ & $201(16.20)$ & $14(11.48)$ & \\
\hline 2017 & $423(11.21)$ & $175(14.10)$ & $8(6.56)$ & \\
\hline Illness onset season & & & & $<0.01$ \\
\hline spring & $614(16.28)$ & $245(19.74)$ & $23(18.85)$ & \\
\hline summer & $1042(27.62)$ & $507(40.85)$ & $57(46.72)$ & \\
\hline autumn & $1343(35.60)$ & $278(22.40)$ & 25 (20.49) & \\
\hline winter & 773 (20.49) & $211(17.00)$ & $17(13.93)$ & \\
\hline
\end{tabular}

\section{Distributions Pm2.5 And Its Components Exposure}

Table 3 shows the average distribution of children exposure to $\mathrm{PM}_{2.5}$ and its components $\left(\mathrm{OM}, \mathrm{BC}, \mathrm{SO}_{4}{ }^{2-}\right.$, $\mathrm{NH}_{4}{ }^{+}$, NIT, SOIL, and SS) 3, 7 and 14 days prior to hospitalization. During 3 days before hospitalization, the median concentrations was $50.00 \mu \mathrm{g} / \mathrm{m}^{3}$ of $\mathrm{PM}_{2.5}, 50.00 \mu \mathrm{g} / \mathrm{m}^{3}$ and $50.02 \mu \mathrm{g} / \mathrm{m}^{3}$ for 7 days and 14 days before hospitalization, respectively. The detailed distributions of $\mathrm{PM}_{2.5}$ and its components for 3,7 
and 14 days before hospitalization are presented in Table 3. The correlations between $\mathrm{PM}_{2.5}$ and its components were shown in Figure S1, Figure S2 and Figure S3. 
Table 3

The distribution of exposure to $\mathrm{PM}_{2.5}$ and is components within different periods.

\begin{tabular}{|c|c|c|c|c|c|c|c|}
\hline & Mean $\pm S D$ & 5th & 25th & 50th & 75th & 95th & Range \\
\hline \multicolumn{8}{|c|}{ Three days before hospitalization $\left(\mu \mathrm{g} / \mathrm{m}^{3}\right)$} \\
\hline $\mathrm{PM}_{2.5}$ & $53.99 \pm 18.79$ & 28.90 & 38.00 & 50.00 & 66.85 & 90.00 & $(21.00,118.90)$ \\
\hline $\mathrm{OM}$ & $8.40 \pm 7.13$ & 2.30 & 3.60 & 5.30 & 11.10 & 25.50 & $(1.70,34.10)$ \\
\hline $\mathrm{BC}$ & $3.78 \pm 1.55$ & 1.70 & 2.60 & 3.40 & 4.90 & 6.60 & $(1.40,8.70)$ \\
\hline $\mathrm{SO}_{4}^{2-}$ & $12.62 \pm 5.26$ & 6.20 & 8.80 & 12.00 & 14.90 & 21.43 & $(4.90,38.30)$ \\
\hline $\mathrm{NH}_{4}^{+}$ & $8.65 \pm 2.69$ & 4.80 & 6.80 & 8.40 & 10.20 & 13.70 & $(3.50,19.60)$ \\
\hline NIT & $13.63 \pm 7.26$ & 4.80 & 7.90 & 12.00 & 18.01 & 27.70 & $(3.40,41.70)$ \\
\hline SOIL & $5.38 \pm 5.82$ & 0.10 & 0.50 & 4.00 & 8.60 & 14.30 & $(0.10,38.80)$ \\
\hline SS & $0.26 \pm 0.18$ & 0.10 & 0.10 & 0.20 & 0.30 & 0.70 & $(0.10,1.50)$ \\
\hline \multicolumn{8}{|c|}{ One week before hospitalization $\left(\mu \mathrm{g} / \mathrm{m}^{3}\right)$} \\
\hline $\mathrm{PM}_{2.5}$ & $53.94 \pm 18.59$ & 29.00 & 38.00 & 50.00 & 66.60 & 90.00 & $(21.00,118.90)$ \\
\hline $\mathrm{OM}$ & $8.36 \pm 7.03$ & 2.30 & 3.60 & 5.31 & 10.90 & 25.00 & $(1.70,34.10)$ \\
\hline $\mathrm{BC}$ & $3.78 \pm 1.54$ & 1.72 & 2.60 & 3.41 & 4.90 & 6.59 & $(1.40,8.70)$ \\
\hline $\mathrm{SO}_{4}{ }^{2-}$ & $12.66 \pm 5.28$ & 6.20 & 8.89 & 12.00 & 15.00 & 21.70 & $(4.90,38.30)$ \\
\hline $\mathrm{NH}_{4}^{+}$ & $8.66 \pm 2.68$ & 4.90 & 6.80 & 8.40 & 10.20 & 13.70 & $(3.50,19.60)$ \\
\hline NIT & $13.61 \pm 7.21$ & 4.90 & 7.90 & 12.00 & 18.00 & 27.60 & $(3.40,41.70)$ \\
\hline SOIL & $5.35 \pm 5.73$ & 0.18 & 0.50 & 4.00 & 8.54 & 14.20 & $(0.10,38.80)$ \\
\hline SS & $0.27 \pm 0.18$ & 0.10 & 0.10 & 0.20 & 0.30 & 0.70 & $(0.10,1.50)$ \\
\hline \multicolumn{8}{|c|}{ Two weeks before hospitalization $\left(\mu \mathrm{g} / \mathrm{m}^{3}\right)$} \\
\hline $\mathrm{PM}_{2.5}$ & $53.83 \pm 18.20$ & 29.00 & 38.60 & 50.20 & 66.13 & 89.13 & $(24.00,118.90)$ \\
\hline $\mathrm{OM}$ & $8.26 \pm 6.83$ & 2.40 & 3.60 & 5.33 & 10.57 & 24.49 & $(1.80,34.10)$ \\
\hline $\mathrm{BC}$ & $3.76 \pm 1.50$ & 1.75 & 2.60 & 3.42 & 4.86 & 6.50 & $(1.40,8.70)$ \\
\hline $\mathrm{SO}_{4}{ }^{2-}$ & $12.75 \pm 5.30$ & 6.30 & 8.95 & 12.00 & 15.10 & 21.89 & $(4.90,38.30)$ \\
\hline $\mathrm{NH}_{4}^{+}$ & $8.67 \pm 2.68$ & 4.95 & 6.80 & 8.50 & 10.20 & 13.69 & $(3.60,19.60)$ \\
\hline
\end{tabular}




\begin{tabular}{|lccccccl|}
\hline & Mean \pm SD & 5th & 25th & 50th & 75th & 95th & Range \\
\hline NIT & $13.56 \pm 7.10$ & 4.99 & 7.93 & 12.00 & 17.80 & 27.50 & $(3.40,41.70)$ \\
\hline SOIL & $5.31 \pm 5.55$ & 0.20 & 0.60 & 4.00 & 8.46 & 14.00 & $(0.10,38.80)$ \\
\hline SS & $0.27 \pm 0.18$ & 0.10 & 0.11 & 0.20 & 0.30 & 0.70 & $(0.06,1.18)$ \\
\hline
\end{tabular}

The association between $\mathrm{PM}_{2.5}$ and its components exposure and the LOS of HFMD

As show in Figure 2 and Table S1, Table S2 and Table S3, the crude and adjusted estimate values and $95 \%$ confidence interval $(95 \% \mathrm{Cl})$ per IQR of $\mathrm{PM}_{2.5}$ increase on the hospital LOS was $0.15(0.02,0.28)$ and $0.52(0.33,0.71)$ at lag 3 days. For lag 7 days, per IQR increase of $\mathrm{PM}_{2.5}$ corresponded to a $0.15(95 \% \mathrm{Cl}$, $0.02-0.29)$ and $0.50(95 \% \mathrm{Cl}, 0.31-0.69)$ increase in the LOS in crude and adjusted models, respectively. For lag 14 days, an IQR increase in $\mathrm{PM}_{2.5}$ concentrations corresponded to a $0.17(95 \% \mathrm{Cl}, 0.04-0.30)$ and $0.46(95 \% \mathrm{Cl}, 0.28-0.65)$ increase in the hospital LOS, respectively.

In the unadjusted model, we noted that positive associations of per IQR increase of $\mathrm{OM}, \mathrm{SO}_{4}{ }^{2-}, \mathrm{NH}_{4}{ }^{+}$and SS with the LOS of HFMD at lag 3 days, 7 days and 14 days, there were no association between BC, NIT and SOIL with the LOS of HFMD at lag 3 days, 7 days and 14 days. After adjusting for age, gender, illness onset year and illness onset season, we found that per IQR increase of $\mathrm{BC}, \mathrm{SO}_{4}{ }^{2-}, \mathrm{NH}_{4}{ }^{+}, \mathrm{NIT}$ and SOIL were significantly associated with the LOS of HFMD at lag 3 days, 7 days and 14 days, but OM and SS were not associated with the LOS of HFMD at lag 3 days, 7 days and 14 days. The detailed data of the relationship between $\mathrm{PM}_{2.5}$ and its components and the LOS of HFMD at lag 3 days, 7 days and 14 days were showed in Table S1, Table S2 and Table S3.

\section{Discussion}

Pollutants such as $\mathrm{PM}_{2.5}$ are polluting the environment seriously, causing numerous health problems(Manisalidis et al. 2020). Many time-series studies have used $\mathrm{PM}_{2.5}$ as an exposure indicator(Atkinson et al. 2014). However, HFMD hospitalization caused by $\mathrm{PM}_{2.5}$ has been little reported so far. To our knowledge, the topic of the clinic demographic features by the LOS is scarce in Chinese children. Long LOS will not only seriously reduce the turnover rate of scarce bed resources in the hospitals and reduce the throughput of patients, but also increase the financial burden on the families of children(Cosgrove 2006, Rahmqvist et al. 2016). Analyzing the LOS of HFMD is important for hospital administrators to formulate countermeasures, improve hospital work efficiency, and control excessive medical expenses. Therefore, we described the clinic demographic features and the LOS of HFMD in 
children's hospital of Nanjing medical university during 2012-2017 in Nanjing, China. Meanwhile, we conducted the relationship between the exposure of $\mathrm{PM}_{2.5}$ and its components and the LOS of HFMD.

The incidence of HFMD in China has been reported to be 1-2 per 1,000 people(Xing et al. 2014). In our research, the incidence of hospitalized HFMD peaked in children aged 1 year and then decreased with age, over $98 \%$ of hospitalized HFMD cases occur in children younger than 6 years of age, which was consistent with the findings in other studies(Baek et al. 2020b, Chen et al. 2007, Podin et al. 2006). Therefore, measures must be taken to prevent HFMD in these key population groups. There was a difference in gender-specific hospital admission, the same results were reported in previous study(Chen et al. 2019, Hoang et al. 2019, Wang et al. 2020), Although infection rates between males and females are comparable, males are more likely to develop symptoms, more involved in the propagation of outbreaks, and more likely to be brought in for medical care than females(Baek et al. 2020b), the reason for the differences observed in gender is not known exactly. The cases of hospitalized HFMD tended to arise in the warmer season (summer and autumn) of the year. Nanjing has strong sunshine, high temperature and heavy rainfall in summer and autumn, and it has a more serious greenhouse effect. We estimate the sunshine, temperature and humidity might explain the seasonality of HFMD(Huang et al. 2013, Onozuka \&Hashizume 2011).

The cases of hospitalized HFMD were the highest in 2013, and then slightly decreased from 2014 to 2017, especially in 2017, the number of hospitalized HFMD was the lowest. The promulgations of the guidelines for HFMD can reduce the number of inpatients through standardized diagnosis and treatment in outpatient. Meanwhile, the guidelines introduce measures for personal protection, family protection, kindergarten or school prevention and management, thus reducing the incidence of hand foot and mouth disease(Ma et al. 2011). EV71 infections are one of the main etiological agents of HFMD, on December 2015, the China Food and Drug Administration (CFDA) approved the first inactivated EV71 whole virus vaccine for preventing severe HFMD. EV71 vaccination could decrease HFMD incidence significantly among children aged two to five years(Wang et al. 2021). In children, the EV71 vaccine elicited EV71specific immune response, less EV71-associated HFMD cases have been observed. One real-world study provided evidence of EV71 vaccine effectiveness for preventing EV71 and "other" viruses associated with HFMD(Du et al. 2021).

In our research, most of inpatient children with HFMD were hospitalized for less than 7 days, followed by 7 to 14 days, and few were hospitalized for more than 14 days. Children aged 1 year, illness onset in summer and 2012 were most likely to be hospitalized for more than 14 days. In 2012, the number of inpatient children with HFMD exceeded 14 days was the largest, followed by 2013 and 2014, then it decreased significantly since 2015 , which was related to the gradual improvement of the diagnosis and treatment of HFMD. The number of children hospitalized for more than 14 days in summer may be related to the increase of nosocomial infections caused by high temperature and high humidity in summer(Eber et al. 2011). The number of children hospitalized for more than 14 days is also higher in aged 1-6 than that of other age groups. In terms of hospitalization management, more attention should be paid to these individuals. 
Previous studies showed that $\mathrm{PM}_{2.5}$ has a higher influence on hospital admission than other air pollutants(Buczyńska et al. 2014). PM 2.5 was positively associated with LOS among children(Baek et al. 2020a). There was a short-term increase in hospital admission rates associated with $\mathrm{PM}_{2.5}$ for all of the health outcomes except injuries(Dominici et al. 2006). Our study showed that short-term exposure to $\mathrm{PM}_{2.5}$ was positively associated with the LOS of HFMD. Our findings were broadly consistent with those studies(Bell et al. 2009, Zhong et al. 2018). It has been demonstrated that exposure to $\mathrm{PM}_{2.5}$ could adversely affect vascular endothelial function, the activity of the sympathetic nervous system, and systemic inflammation, leading to vasoconstriction, increased plasma viscosity, and a risk of blood clotting and thrombosis(Liu et al. 2017). These adverse effects can exacerbate the child's symptoms, therefore increase the LOS of HFMD.

In addition, in our research, $\mathrm{SO}_{4}{ }^{2-}$ was the most significantly associated component of $\mathrm{PM}_{2.5}$ with the LOS of HFMD followed by $\mathrm{NH}_{4}{ }^{+}$, SOIL, NIT and BC. $\mathrm{SO}_{4}{ }^{2-}$ and $\mathrm{NH}_{4}{ }^{+}$were the secondary pollutants and mainly concentrated in power plants dust, motor vehicle exhaust and construction dust, generally higher values were found during summer and spring months. $\mathrm{SO}_{4}{ }^{2-}$ is mostly regionally transported in the summer, various studies have linked sulfate exposure with adverse respiratory and cardiovascular effects, as well as mortality(Nunez et al. 2021).

The $\mathrm{BC}$ component of $\mathrm{PM}_{2.5}$ consists of soot, charcoal, char, and other light absorbing refractory matter. Although the health impacts of BC have been extensively studied(Clifford et al. 2016, Nunez et al. 2021), its association with HFMD is not as well characterized. In Nanjing, we found an expected association between BC exposure and the LOS of HFMD, our research has enriched the epidemiological information on the health impacts of BC on HFMD. NIT is mainly a secondary particle found in the atmosphere, unlike the adverse health effects of BC exposure, NIT exposure have been less explored (Cao et al. 2012).

The SS originate $\mathrm{Cl}^{-}, \mathrm{Na}^{+}$, and $\mathrm{Mg}^{2+}$ and is variable during winter months because of unsettled weather conditions in winter season(Kocak et al. 2015), in our study, the cases of hospitalized HFMD tended to arise in the warmer season. The OM is a highly complex mixture of hundreds of compounds such as organic carbon, polycyclic aromatic hydrocarbons, alkanes, and fatty acids, but the health effects of OM remain largely uncharacterized, we did not find the association between OM exposure and the LOS of HFMD, these findings need to be further confirmed.

Our study had advantages. We focused on the epidemiologic features of the LOS of HFMD in the Chinese population and the relationship between the exposure of $\mathrm{PM}_{2.5}$ and its components and the LOS of HFMD. This is a topic that has not received much attention and will provide a basis for hospital management. $\mathrm{PM}_{2.5}$ exposure is associated with the increased LOS of HFMD, and its components (BC, $\mathrm{SO}_{4}{ }^{2-}, \mathrm{NH}_{4}{ }^{+}, \mathrm{NIT}$ and SOIL) of $\mathrm{PM}_{2.5}$ might play a key role in the prolonged LOS of HFMD. Our findings call for greater awareness of environmental protection and the implementation of effective measures to improve the quality of air, which may reduce the risks of adverse effects on children. Policy changes to 
reduce outdoor air pollutant exposure may lead to improved HFMD outcomes and substantial savings in healthcare spending.

Our study had limitations. Some covariates are unmeasured, such as the socioeconomic and educational status of the parents. Although our observational study was completed in a representative city in China and lasted for 7 years, the sample size included is still relatively small, and larger sample size is needed to support the research results. In our study, we focus on $\mathrm{PM}_{2.5}$, other air pollutants such as nitrogen dioxide $\left(\mathrm{NO}_{2}\right)$, ozone $\left(\mathrm{O}_{3}\right)$ and carbon monoxide (CO) might also contribute to the LOS of HFMD.

\section{Conclusion}

Short-term $\mathrm{PM}_{2.5}$ and its components (BC, $\mathrm{SO}_{4}{ }^{2-}, \mathrm{NH}_{4}{ }^{+}$, NIT and SOIL) exposure might increase the LOS of HFMD. Improving the quality of air could help to reduce the burden of HFMD.

\section{Declarations}

\section{Ethics approval and consent to participate}

All participating subjects received written detailed information on the study, and signed consent forms for the interview and the processing of sensitive personal data.

\section{Consent for publication}

We have submitted our manuscript to research square (DOI: 10.21203/rs.3.rs-986232/v1)

\section{Availability of data and materials}

The datasets analyzed in this study are available from the corresponding authorafter coauthors' approval of the request.

\section{Competing interests:}

The authors declare that they have no competing interests.

\section{Funding}

None.

\section{Authors' contributions}

Wei Li: Methodology, Software, Formal analysis, Writing. Jieguo Wang: Conceptualization, Project administration, Writing. Kai Zhou: Data Curation. Ye Tian: Conceptualization, Writing. Feiran Wei: Methodology. Mingzhi Zhang and Xu Wang: Conceptualization, Supervision, Writing. The author(s) read and approved the fnal manuscript. 


\section{References}

1. Atkinson RW, Kang S, Anderson HR, Mills IC, Walton HA (2014): Epidemiological time series studies of PM2.5 and daily mortality and hospital admissions: a systematic review and meta-analysis. Thorax 69, 660-5

2. Baek J, Kash BA, Xu X, Benden M, Roberts J, Carrillo G (2020a): Association between Ambient Air Pollution and Hospital Length of Stay among Children with Asthma in South Texas. International journal of environmental research and public health 17

3. Baek S, Park S, Park HK, Chun BC (2020b): The epidemiological characteristics and spatio-temporal analysis of childhood hand, foot and mouth disease in Korea, 2011-2017. PLoS One 15, e0227803

4. Bell ML, Ebisu K, Peng RD, Samet JM, Dominici F (2009): Hospital admissions and chemical composition of fine particle air pollution. Am J Respir Crit Care Med 179, 1115-20

5. Blomqvist S, Klemola P, Kaijalainen S, Paananen A, Simonen ML, Vuorinen T, Roivainen M (2010): Cocirculation of coxsackieviruses $\mathrm{A} 6$ and $\mathrm{A} 10$ in hand, foot and mouth disease outbreak in Finland. J Clin Virol 48, 49-54

6. Buczyńska AJ, Krata A, Van Grieken R, Brown A, Polezer G, De Wael K, Potgieter-Vermaak S (2014): Composition of PM2.5 and PM1 on high and low pollution event days and its relation to indoor air quality in a home for the elderly. The Science of the total environment 490, 134-43

7. Cao J, Xu H, Xu Q, Chen B, Kan H (2012): Fine particulate matter constituents and cardiopulmonary mortality in a heavily polluted Chinese city. Environ Health Perspect 120, 373-8

8. Chang LY, Huang YC, Lin TY (1998): Fulminant neurogenic pulmonary oedema with hand, foot, and mouth disease. Lancet 352, 367-8

9. Chen KT, Chang HL, Wang ST, Cheng YT, Yang JY (2007): Epidemiologic features of hand-foot-mouth disease and herpangina caused by enterovirus 71 in Taiwan, 1998-2005. Pediatrics 120, e244-52

10. Chen Q, Zhang Q, Hu Z (2019): Profiles of Human Enteroviruses Associated with Hand, Foot, and Mouth Disease in Nanjing, China. Disaster Med Public Health Prep 13, 740-744

11. Clifford A, Lang L, Chen R, Anstey KJ, Seaton A (2016): Exposure to air pollution and cognitive functioning across the life course-A systematic literature review. Environ Res 147, 383-98

12. Cosgrove SE (2006): The relationship between antimicrobial resistance and patient outcomes: mortality, length of hospital stay, and health care costs. Clin Infect Dis 42 Suppl 2, S82-9

13. Dominici F, Peng RD, Bell ML, Pham L, McDermott A, Zeger SL, Samet JM (2006): Fine particulate air pollution and hospital admission for cardiovascular and respiratory diseases. JAMA 295, 1127-34

14. Du Z, Huang Y, Bloom MS, Zhang Z, Yang Z, Lu J, Xu J, Hao Y (2021): Assessing the vaccine effectiveness for hand, foot, and mouth disease in Guangzhou, China: a time-series analysis. Human 
vaccines \& immunotherapeutics $17,217-223$

15. Duan C, Zhang X, Jin H, Cheng X, Wang D, Bao C, Zhou M, Ahmad T, Min J (2018): Meteorological factors and its association with hand, foot and mouth disease in Southeast and East Asia areas: a meta-analysis. Epidemiol Infect, 1-18

16. Eber MR, Shardell M, Schweizer ML, Laxminarayan R, Perencevich EN (2011): Seasonal and temperature-associated increases in gram-negative bacterial bloodstream infections among hospitalized patients. PLoS One 6, e25298

17. Han J, Wang Y, Gan X, Song J, Sun P, Dong XP (2014): Serum cytokine profiles of children with human enterovirus 71-associated hand, foot, and mouth disease. J Med Virol 86, 1377-85

18. Hao J, Yang Z, Yang W, Huang S, Tian L, Zhu Z, Lu Y, Xiang H, Liu S (2020): Impact of Ambient Temperature and Relative Humidity on the Incidence of Hand-Foot-Mouth Disease in Wuhan, China. International journal of environmental research and public health 17

19. Hoang MTV et al. (2019): Clinical and aetiological study of hand, foot and mouth disease in southern Vietnam, 2013-2015: Inpatients and outpatients. Int J Infect Dis 80, 1-9

20. Hu YF, Yang F, Du J, Zhang T, Xue Y, Jin Q (2012): Coxsackievirus B5, associated with neurological hand, foot and mouth disease, China. J Infect 65, 189-91

21. Huang J, Liao Q, Ooi MH, Cowling BJ, Chang Z, Wu P, Liu F, Li Y, Luo L, Yu S, Yu H, Wei S (2018): Epidemiology of Recurrent Hand, Foot and Mouth Disease, China, 2008-2015. Emerg Infect Dis 24

22. Huang R, Ning H, He T, Bian G, Hu J, Xu G (2019): Impact of PM(10) and meteorological factors on the incidence of hand, foot, and mouth disease in female children in Ningbo, China: a spatiotemporal and time-series study. Environmental science and pollution research international 26, 17974-17985

23. Huang Y, Deng T, Yu S, Gu J, Huang C, Xiao G, Hao Y (2013): Effect of meteorological variables on the incidence of hand, foot, and mouth disease in children: a time-series analysis in Guangzhou, China. BMC Infect Dis 13, 134

24. Kocak M, Mihalopoulos N, Tutsak E, Theodosi C, Zarmpas P, Kalegeri P (2015): PM10 and PM2.5 composition over the Central Black Sea: origin and seasonal variability. Environmental science and pollution research international 22, 18076-92

25. Koh WM, Bogich T, Siegel K, Jin J, Chong EY, Tan CY, Chen MI, Horby P, Cook AR (2016): The Epidemiology of Hand, Foot and Mouth Disease in Asia: A Systematic Review and Analysis. Pediatr Infect Dis J 35, e285-300

26. Li Y, Henze DK, Jack D, Kinney PL (2016): The influence of air quality model resolution on health impact assessment for fine particulate matter and its components. Air quality, atmosphere, \& health 9, 51-68

27. Liu H, Tian Y, Xu Y, Zhang J (2017): Ambient Particulate Matter Concentrations and Hospitalization for Stroke in 26 Chinese Cities: A Case-Crossover Study. Stroke 48, 2052-2059

28. Ma E, Chan KC, Cheng P, Wong C, Chuang SK (2010): The enterovirus 71 epidemic in 2008--public health implications for Hong Kong. Int J Infect Dis 14, e775-80 
29. Ma E, Wong S, Wong C, Chuang SK, Tsang T (2011): Effects of public health interventions in reducing transmission of hand, foot, and mouth disease. Pediatr Infect Dis J 30, 432-5

30. Manisalidis I, Stavropoulou E, Stavropoulos A, Bezirtzoglou E (2020): Environmental and Health Impacts of Air Pollution: A Review. Front Public Health 8, 14

31. Mirand A, Henquell C, Archimbaud C, Ughetto S, Antona D, Bailly JL, Peigue-Lafeuille H (2012): Outbreak of hand, foot and mouth disease/herpangina associated with coxsackievirus A6 and A10 infections in 2010, France: a large citywide, prospective observational study. Clin Microbiol Infect 18, E110-8

32. Mukherjee A, Agrawal M (2018): A Global Perspective of Fine Particulate Matter Pollution and Its Health Effects. Reviews of environmental contamination and toxicology 244, 5-51

33. Nunez Y, Boehme AK, Li M, Goldsmith J, Weisskopf MG, Re DB, Navas-Acien A, van Donkelaar A, Martin RV, Kioumourtzoglou MA (2021): Parkinson's disease aggravation in association with fine particle components in New York State. Environ Res 201, 111554

34. Onozuka D, Hashizume M (2011): The influence of temperature and humidity on the incidence of hand, foot, and mouth disease in Japan. The Science of the total environment 410-411, 119-25

35. Podin Y, Gias EL, Ong F, Leong YW, Yee SF, Yusof MA, Perera D, Teo B, Wee TY, Yao SC, Yao SK, Kiyu A, Arif MT, Cardosa MJ (2006): Sentinel surveillance for human enterovirus 71 in Sarawak, Malaysia: lessons from the first 7 years. BMC Public Health 6, 180

36. Rahmqvist M, Samuelsson A, Bastami S, Rutberg H (2016): Direct health care costs and length of hospital stay related to health care-acquired infections in adult patients based on point prevalence measurements. Am J Infect Control 44, 500-6

37. Repass GL, Palmer WC, Stancampiano FF (2014): Hand, foot, and mouth disease: identifying and managing an acute viral syndrome. Cleve Clin J Med 81, 537-43

38. Tian S, Liu Y, Wang J, Wang J, Hou L, Lv B, Wang X, Zhao X, Yang W, Geng C, Han B, Bai Z (2020): Chemical Compositions and Source Analysis of PM2.5 during Autumn and Winter in a Heavily Polluted City in China. Atmosphere 11

39. van Donkelaar A, Martin RV, Brauer M, Hsu NC, Kahn RA, Levy RC, Lyapustin A, Sayer AM, Winker DM (2016): Global Estimates of Fine Particulate Matter using a Combined Geophysical-Statistical Method with Information from Satellites, Models, and Monitors. Environ Sci Technol 50, 3762-72

40. van Donkelaar A, Martin RV, Li C, Burnett RT (2019): Regional Estimates of Chemical Composition of Fine Particulate Matter Using a Combined Geoscience-Statistical Method with Information from Satellites, Models, and Monitors. Environ Sci Technol 53, 2595-2611

41. Wang J, Zhou J, Xie G, Zheng S, Lou B, Chen Y, Wu Y (2020): The Epidemiological and Clinical Characteristics of Hand, Foot, and Mouth Disease in Hangzhou, China, 2016 to 2018. Clin Pediatr (Phila) 59, 656-662

42. Wang X, Zhu D, Yuan S (2021): Impact of enterovirus 71 vaccine vaccination on incidence of hand, foot and mouth disease among children in China mainland: an interrupted time series analysis. Chin J Public Health, 1-3 
43. Wang YR, Sun LL, Xiao WL, Chen LY, Wang XF, Pan DM (2013): Epidemiology and clinical characteristics of hand foot, and mouth disease in a Shenzhen sentinel hospital from 2009 to 2011. BMC Infect Dis 13, 539

44. Xing W, Liao Q, Viboud C, Zhang J, Sun J, Wu JT, Chang Z, Liu F, Fang VJ, Zheng Y, Cowling BJ, Varma JK, Farrar JJ, Leung GM, Yu H (2014): Hand, foot, and mouth disease in China, 2008-12: an epidemiological study. Lancet Infect Dis 14, 308-318

45. Yu G, Li Y, Cai J, Yu D, Tang J, Zhai W, Wei Y, Chen S, Chen Q, Qin J (2019): Short-term effects of meteorological factors and air pollution on childhood hand-foot-mouth disease in Guilin, China. The Science of the total environment $646,460-470$

46. Zhong R, Wu Y, Cai Y, Wang R, Zheng J, Lin D, Wu H, Li Y (2018): Forecasting hand, foot, and mouth disease in Shenzhen based on daily level clinical data and multiple environmental factors. Bioscience trends 12, 450-455

47. Zou XN, Zhang XZ, Wang B, Qiu YT (2012): Etiologic and epidemiologic analysis of hand, foot, and mouth disease in Guangzhou city: a review of 4,753 cases. Braz J Infect Dis 16, 457-65

\section{Figures}




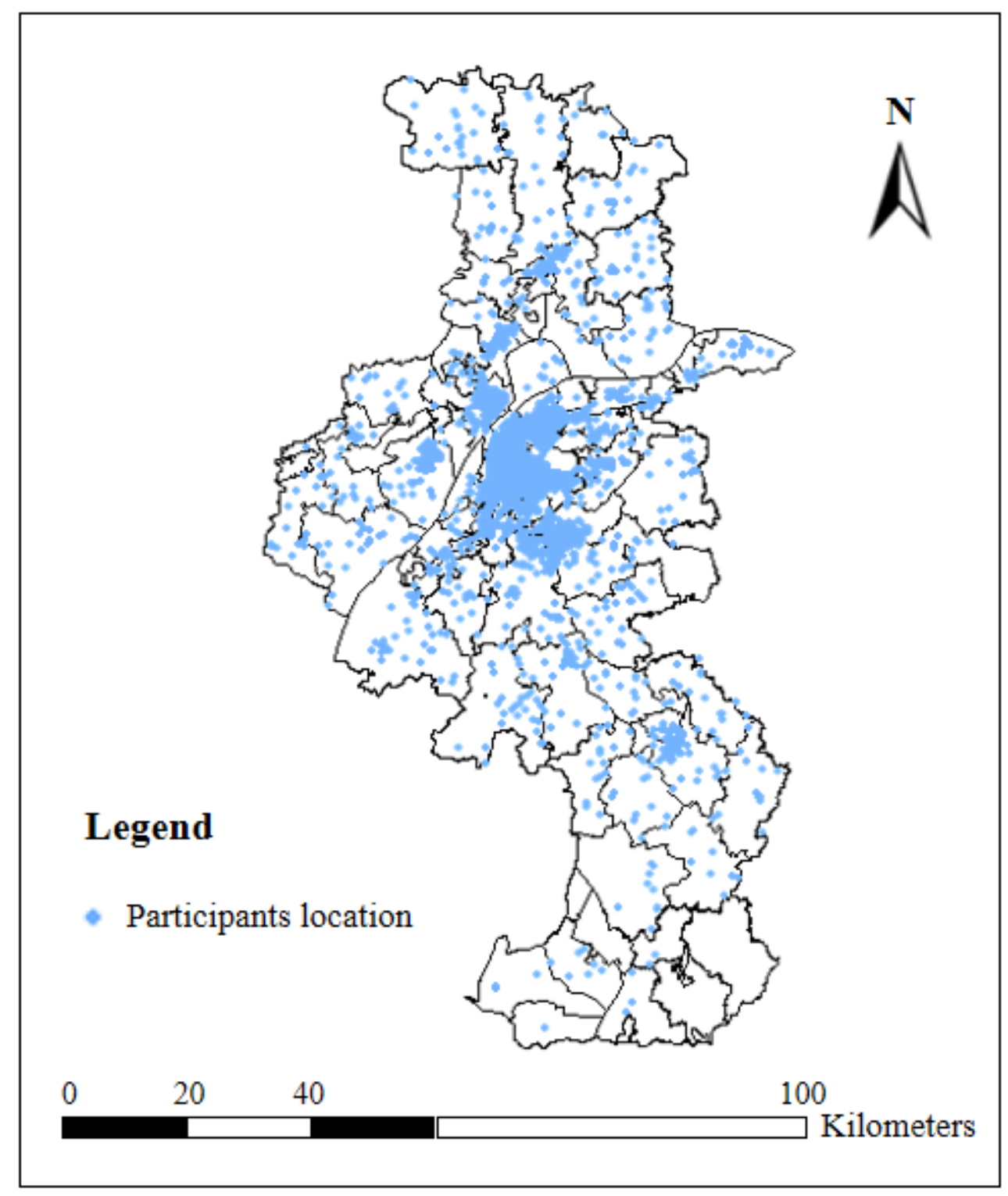

\section{Figure 1}

The distribution of geographical location of participants in Nanjing

\section{Figure 2}

As show in Figure 2, the crude and adjusted estimate values and $95 \%$ confidence interval $(95 \% \mathrm{Cl})$ per IQR of $\mathrm{PM}_{2.5}$ increase on the hospital LOS was $0.15(0.02,0.28)$ and $0.52(0.33,0.71)$ at lag 3 days.

\section{Supplementary Files}

This is a list of supplementary files associated with this preprint. Click to download. 
- Figures1.tif

- Figures2.tif

- Figures3.tif

- TableS1S3.docx 